\title{
NUMERICAL VALIDATION OF WAVE PROPAGATION, TRANSFORMATION AND DISSIPATION TOWARDS A HARBOUR FACILITY: A NEW BECHMARK CASE
}

Diaz-Hernandez G. ${ }^{1}$, Lomonaco P. ${ }^{1}$, Armesto J. A. ${ }^{1}$, and Mendoza A. P. ${ }^{1}$

\begin{abstract}
A new set of experimental data is used in the numerical validation (2DH) of waves propagating towards a scaled harbour facility. The Laredo marina-harbour located at the North coast of Cantabria (Spain), which has lately improved by the extension of its main breakwater, was modelled in the $28 \mathrm{~m}$ long and $8.6 \mathrm{~m}$ wide directional wave basin of the Environmental Hydraulic Institute, at the University of Cantabria. For two months, different 3D tests were simulated for this harbour configuration, starting with the detailed construction of the real bathymetry contour data, and followed by the construction of the $450 \mathrm{~m}$ (trunk and head), of a curved rubble-mound, 1:2 slope breakwater, capped with a variable height L-shaped crownwall and the armour layer is composed of 60 ton (trunk) and 70 ton (roundhead) cubic units.
\end{abstract}

Keywords: pCOULWAVE; Numerical model; Physical model; Breaking wave; Rubble-mound Breakwater

\section{INTRODUCTION}

In nearshore regions, the design of coastal structures commonly requires a compete study of the ocean waves, propagating from deep to shallow water and thus, the study of the interaction of the waves with the different natural and artificial structures, for different layouts and geometries.

Sometimes this sort of real engineering studies, needs an integral comprehension of the main processes which occur near the structures, and all over the effects over surrounding zones, such beaches, harbours, basins, etc.

Because of this, it is highly recommended to approach this kind of engineering studies, through both: an experimental and a numerical approach, in order to measure, observe and quantify the main effects related with each study.

Sometimes this situation is not possible, mainly because laboratory experiments are quite expensive and/or insufficient because of: physical limitations of the experimental facilities: related with the oscillatory fluid processes; experiments are scheduled within a strict calendar; and measurement techniques are limited and generally invasive. Also, numerical approach could be: high CPU time consuming; governing equations are not complete suitable for all the physical situations; and the models used are not well validated or extrapolated for real engineering situations. These situations and limitations are very common in the actual coastal engineering methodology for real studies.

Over the last years, port and coastal engineering has been enormously improved trough numerical modelling of the physical processes associated to the wave-structure interaction; enable us to develop high quality studies with detailed spatial and temporal results.

2DV, 2DH, and fully 3D numeric implementations have proven to be an excellent approximation to the understanding of the oscillatory flow interaction with natural and artificial structures, i.e. depth averaged models such those based on Boussinesq equations (Madsen P.A. et al. 1997; Kennedy A.B. et al. 1997; Chen, Q.R. et al. 1999; Tonelli M. et al. 2009); 2D and 3D CFD models based on the RANS approximation (Garcia N. et al. 2004; Losada, I. et al. 2008; Desombre J. et al. 2013); or fully $3 \mathrm{D}$ implementations that handles physical processes of great complexity (Higuera P. et al. 2012).

Within the models mentioned above, Boussinesq.-type models have experienced a huge advance, especially because the exponential improvement of the CPU processors, the parallelization of the codes, and the adaptation of new post-processing techniques of time series, inherit from the experimental/laboratory field.

This family of models, along with CFD's, bases their technical veracity on an adequate validation job, for different theoretical, analytical, problems, and laboratory and field data.

This is the main reason for the development of the present study: to provide a new dataset which shows the experimental behaviour of irregular and solitary weaves interaction with real bathymetry, and with a rubble-mound breakwater. The aim of this paper is to provide a new open-use benchmark case to be useful for any technician, scientific, or engineer. Thought for numerical modellers and code developers.

\footnotetext{
${ }^{1}$ Environmental Hydraulics Institute "IH Cantabria". Universidad de Cantabria. c /lsabel Torres no 15 39011.Santander. Spain. diazg@unican.es
} 
This new benchmark case agglutinate the following characteristics: real irregular wave data propagating over complex bathymetry; detailed construction of a scaled rubble-mound breakwater; three-dimensional effects, partial reflections, shoaling, refraction, diffraction and breaking phenomena, run-up over the structure and overtopping, and finally, the measurement of long duration series of waves at different zones within the wave tank.

Additionally, in order to show the value of this new experimental database, this paper includes a validation job though the reproduction of two experimental runs, by the use of pCOULWAVE numerical model (Kim et al. 2009), based on the fully non linear and weakly dispersive Boussinesq equations, under a finite volume scheme.

\section{MOTIVATION OF THE STUDY}

The aim of this paper is to introduce a new experimental database tested at the University of Cantabria wave basin, as a new benchmark case for the validation and development of the corresponding numerical models $(2 \mathrm{DH}$ and $3 \mathrm{D})$, designed to propagate, transform and dissipate real wave trains with and without emerged harbour structures.

Especially interesting for any kind of engineer study, related to: 3D breaking, shoaling; diffraction and run-up, over complex bathymetries, and from the trunk to the head of a breakwater.

Secondly, to demonstrate the value of the laboratory database, through the validation of a fully nonlinear and weakly dispersive Boussinesq model, solved by finite volume, which involves a fourthorder MUSCL-TVD scheme to solve the advection, Kim et al. (2009). The model has been validated using classical benchmarks and real cases in (Armesto et al. under review, 2012).

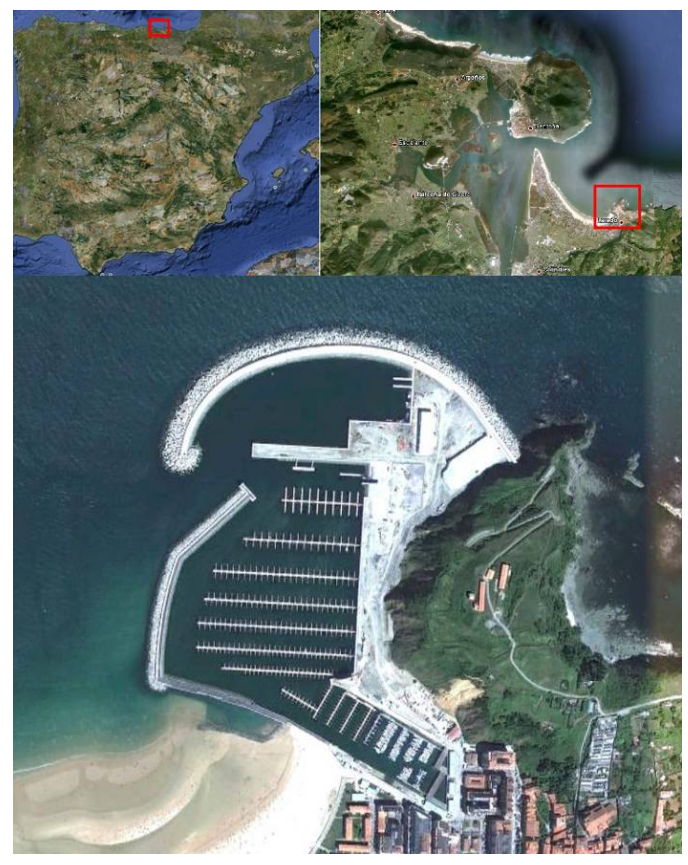

Figure 1. Location and actual geometry of the new Marina located in Laredo, Cantabria, Spain.

\section{LABORATORY MODEL TEST SET-UP}

A 1:45 model scale was established for all the experiments, and different incident wave characteristics were employed (33 irregular waves, 12 solitary waves), for two different mean water levels, corresponding with low and high tide respectively, taking into account two different mean wave directions (perpendicular and $20^{\circ}$ oblique with respect to the symmetry line of the basin).

Tests were executed with and without the presence of the breakwater (undisturbed wave tests as well as stability and overtopping assessment on the breakwater were also performed as part of the study objectives).

In summary, a wide database was obtained for a total of 12 wave gauges, positioned at different study zones: incident, shoaling, breaking, run-up, etc., obtaining high quality free-surface time series 
(of at least 1000 waves for irregular tests), with a measurement frequency of $100 \mathrm{~Hz}$, as well as a quality control system using digital video capturing of some of the wave tests.

The initial aim of the experiments described above, was to study the stability of the armour layer of the new breakwater, located at the Eastern coastal zone of Cantabria, the new Marina in Laredo, Spain (see Fig 1).

Stability analysis was made especially at the head of the breakwater, where high energy waves approaches, breaks and finally displaces the individual cubes.

This objective was achieved in the original project, but the experiments showed a complex behaviour of the waves as they propagate along the basin domain. Complex patterns of shoaling, refraction, breaking, run-up over bathymetry, and over the slope of the structure were observed, and even some episodes of wave overtopping were recorded.

This experiment was carried out along for 2 months of 2011, from February to March, at the multidireccional wave basin of $28 \mathrm{~m}$ long, $8.8 \mathrm{~m}$ wide, and $1.2 \mathrm{high}$, in the University of Cantabria, as part of the facilities of the Environmental Hydraulic Instititute IH-LAB (see Fig. 2).

During these months, works related to the construction of the bathymetry, measurements calibration, forcing time series design, video array setup, as well as general measurements, were done.

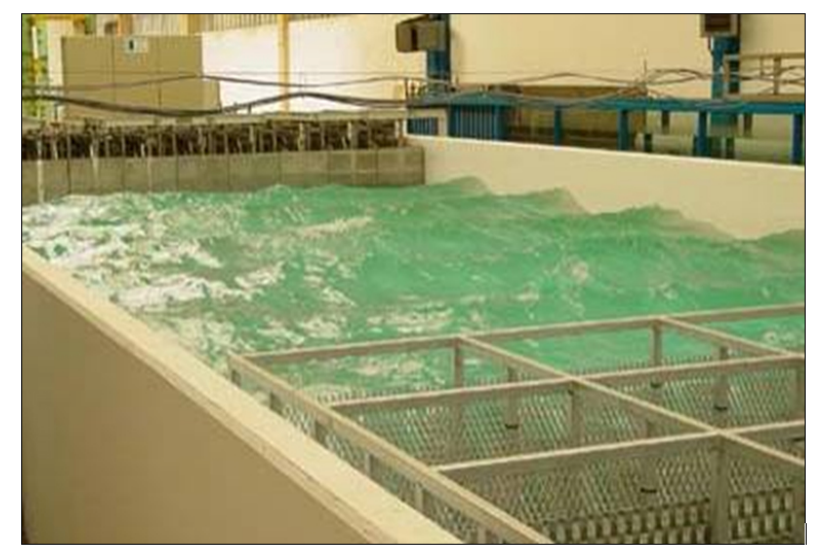

Figure 2. Wave Basin at the University of Cantabria

The wave basin has a 10 piston-type generation system, able to generate any analogical signal within specific velocity and stoke limits. Maximum wave height depends on water depth value at the toe of the generation wall, and on the desired wave period to be generated, i.e. for a water depth of 0.6 $\mathrm{m}$, maximum wave height would be of $0.3 \mathrm{~m}$ for a $3 \mathrm{~s}$ period.

Control system of the generation pistons, are handled trough own-developed software which make a real time control of the stroke position of each piston. Any regular, irregular, multidirectional, group wave train, solitary wave, or focused wave train could be generated in this facility.

The size of the small scale model at the University of Cantabria was selected in order to avoid spurious scale effects, such the wave reflection from contours. Froude scale laws were followed, according to dominant inertia above the gravitational forces. The small scale considered corresponding to scale 1:45 of prototype conditions. This scale was established due a depth limiting value at prototype of $25 \mathrm{~m}$ at the generation zone, taking into account the tide height of $+5.3 \mathrm{~m}$ above low tide level.

Maximum wave height available at generation zone was $15.15 \mathrm{~m}$ and of $8.4 \mathrm{~m}$ at the toe of the structure (depth limited wave height).

Rubble mound structure and bathymetry were rotated, in order to obtain the adequate wave propagation direction of N14E, which correspond to the mean energy wave flux at the study zone.

Fig. 3 shows the bathymetry and structure segment that was included within the wave basin, corresponding to a segment of $276 \mathrm{~m}$ from the middle zone of the body of the structure, to the roundhead. In this model, the inner basins were not considered in the experiments. 


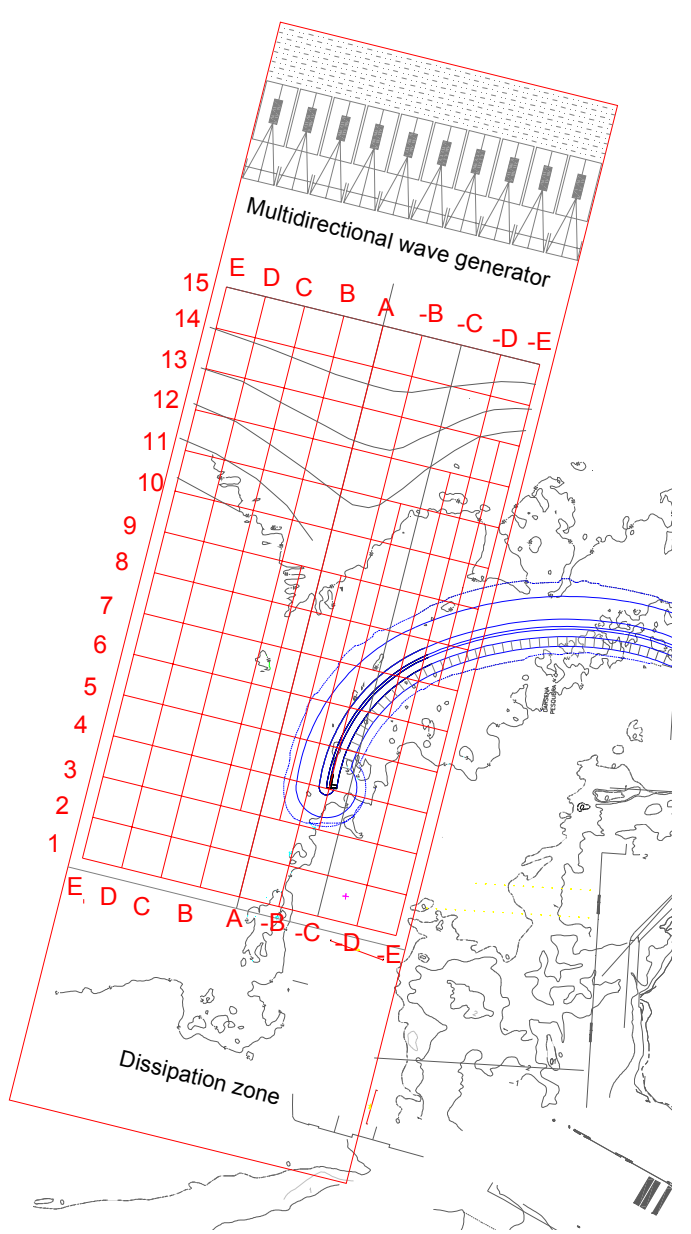

Figure 3. Wave basin layout, wave generation and dissipation zone (in red), 1:45 rubble mound breakwater (blue).

Two phases were needed for the construction of the scaled model within the wave basin: first, by the construction of a detailed bathymetry following a bathymetric field campaign of year 2011; second, by the construction of a segment if the rubble-mound breakwater (see Fig. 3). When the first phase was finished, some wave calibration tests were made.

\section{Construction phase 1 . Bathymetry configuration}

The effectiveness, interpretation and future use of these laboratory data lies, at first place, in a correct bathymetric representation of the study zone, especially at the surroundings of the structure.

Consequentially, an adequate selection of the model scale is crucial for the wave adaptation to the contours as well as, for the stability behaviour of the structure. A scale of 1:45 was selected after some iteration between the geometry of the structure, bathymetry and the wave basin dimensions.

Completely identical concrete bottom configurations were constructed, see Fig. 4. With this bathymetry constructed, first runs were made for the calibration stage of the experiments. 


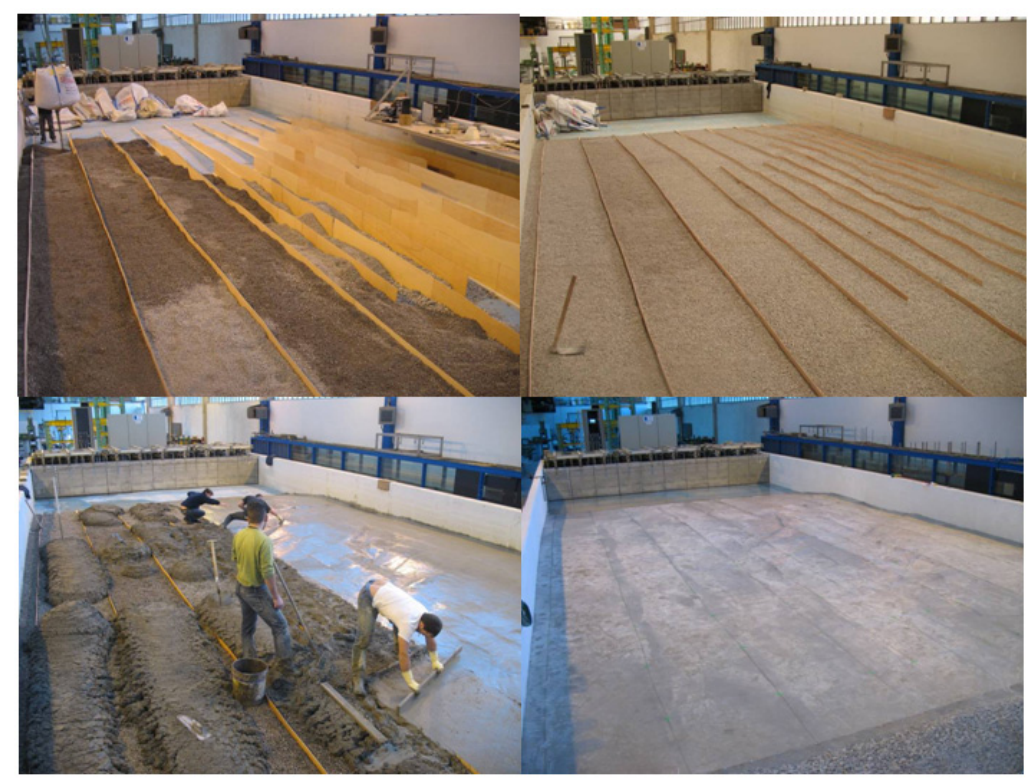

Figure 4. Bathymetry construction: First gravel padding along the longitudinal profiles, concrete flushing and bathymetry completed.

\section{Construction phase 2: Rubble mound breakwater}

Some wood templates were generated, in order to define the envelope of each layer of the rubblemound (see Fig. 5). Rubble-mound material was selected calculating the mean density of the available gravel material. A nominal diameter was obtained and thus, the mean weight was obtained for the core of the structure.

A layer of between 7 and $10 \mathrm{~cm}$ was ready, representing a 300 to $1000 \mathrm{~kg}$ material, and finally, cubic pieces were selected for the representation of the first ( $70 \mathrm{Ton})$, and secondary layer (60 Ton), of the structure (see Fig. 6).

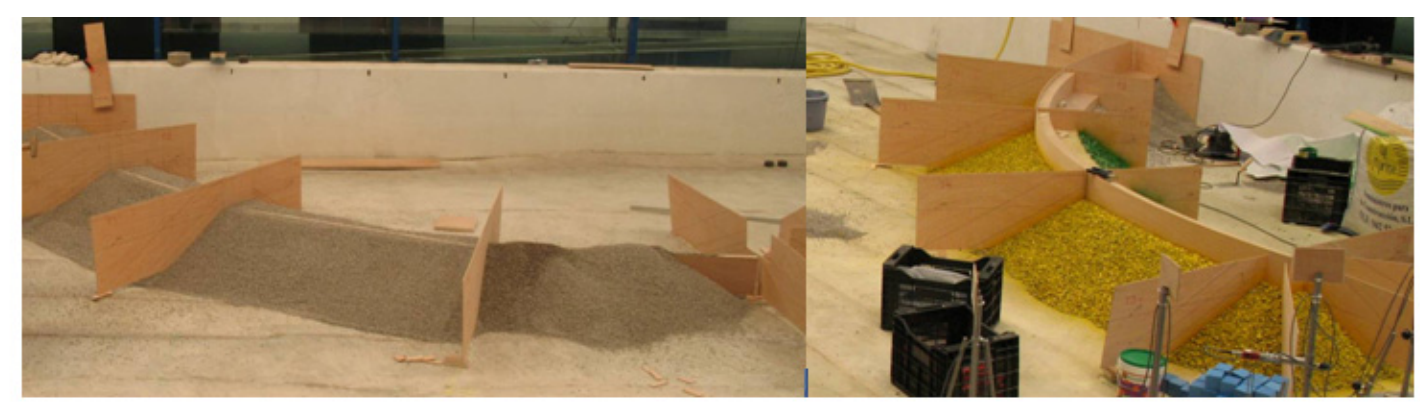

Figure 5. Transversal sections of the scaled structure for the stability test in laboratory.

The crownwall of the structure was made of wood board, following the exact scaled dimension of the constructive project on prototype. 


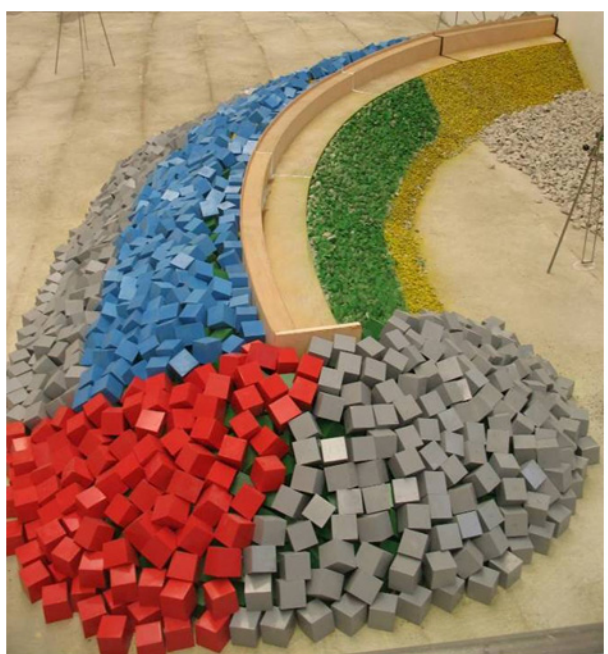

Figure 6. Final layout of the rubble-mound breakwater constructed. 60 Ton cubes (grey and blue) y 70 Ton cubes (red).

Finally, to avoid unexpected reflections of the upcoming waves, some dissipative beaches were constructed at the very end of the wave basin (beside the dissipation zone of the basin). These beaches were built using gravel material.

\section{Wave generation and data analysis}

Combinations of irregular/random sea-states were determined, based on the wave climate of the study zone. Extreme wave regime data and two mean sea levels were taken into account: low and high tide, coinciding with equinoctial tide range at the study zone (tide range of 5 meters).

Significant wave heights between 5 to $10 \mathrm{~m}$, peak periods between 12 and $19 \mathrm{~s}$, for both tide levels were tested in the laboratory wave basin, yielding a total of 33 irregular wave trains. The length of the tests was 1000 waves

Additionally, 12 complementary solitary waves were tested (see appendix).

A TMA spectrum (Bouws et al., 1985a), which is an adaptation of the JONSWAP spectrum for intermediate-shallow waters, was used due the wave basin, due depth limitations of $-25 \mathrm{~m}$ of the wave generation zone. The sample frequency was $100 \mathrm{~Hz}$.

Two test phases were carried out: calibration phase, which only the bathymetry was taken into account (with out the structure); and the stability phase, on which both the bathymetry and the structure were used.

\section{Wave measurements}

Free surface oscillations and video records were measured. This was done by using the layout shown in Fig. 7. The free surface of the waves were measured both in the middle zone of the basin (near the paddle) and at the surroundings of the breakwater. Resistance type twin-wire wave gauges were used. Calibration of the wave gauges were done by filling and take out of water, once per day during filling of the flume. 

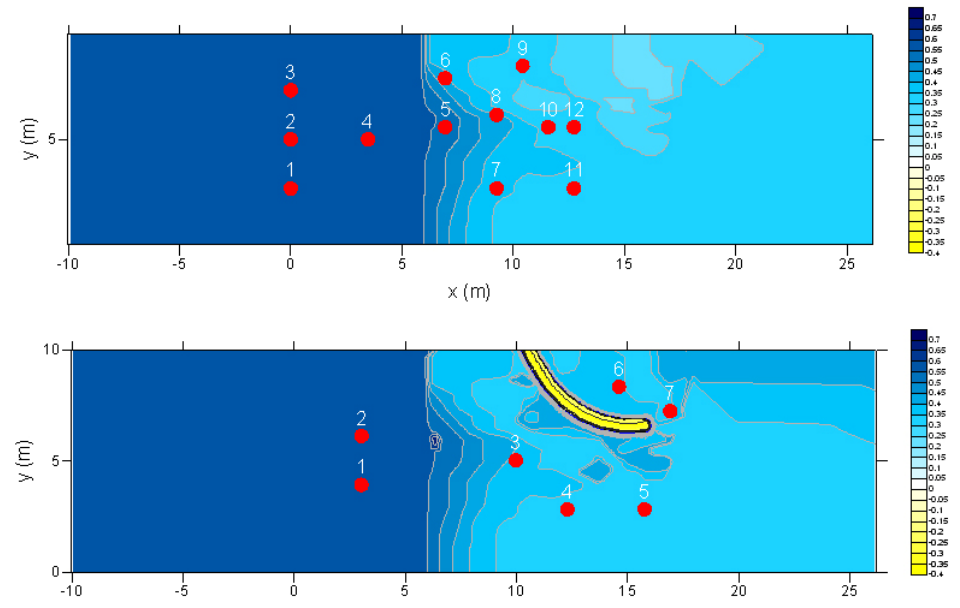

Figure 7. Wave gauges layout for calibration (above) and stability (below) experiments.

(Vidal et al. 2006) showed that the $H_{50}$ parameter, defined as the average of the 50 highest waves in the structures lifetime, can be used to describe the evolution of damage in rubble mound breakwaters attacked by sea states of any duration and wave height distribution. Gauges 8,10 and 12 were used to calibrate the evolution of the $H_{50}$ along the structure; gauge 12 gives the target $\mathrm{H}_{50}$ at the roundhead fixed in the original project as design parameter for the stability of the structure at that zone.

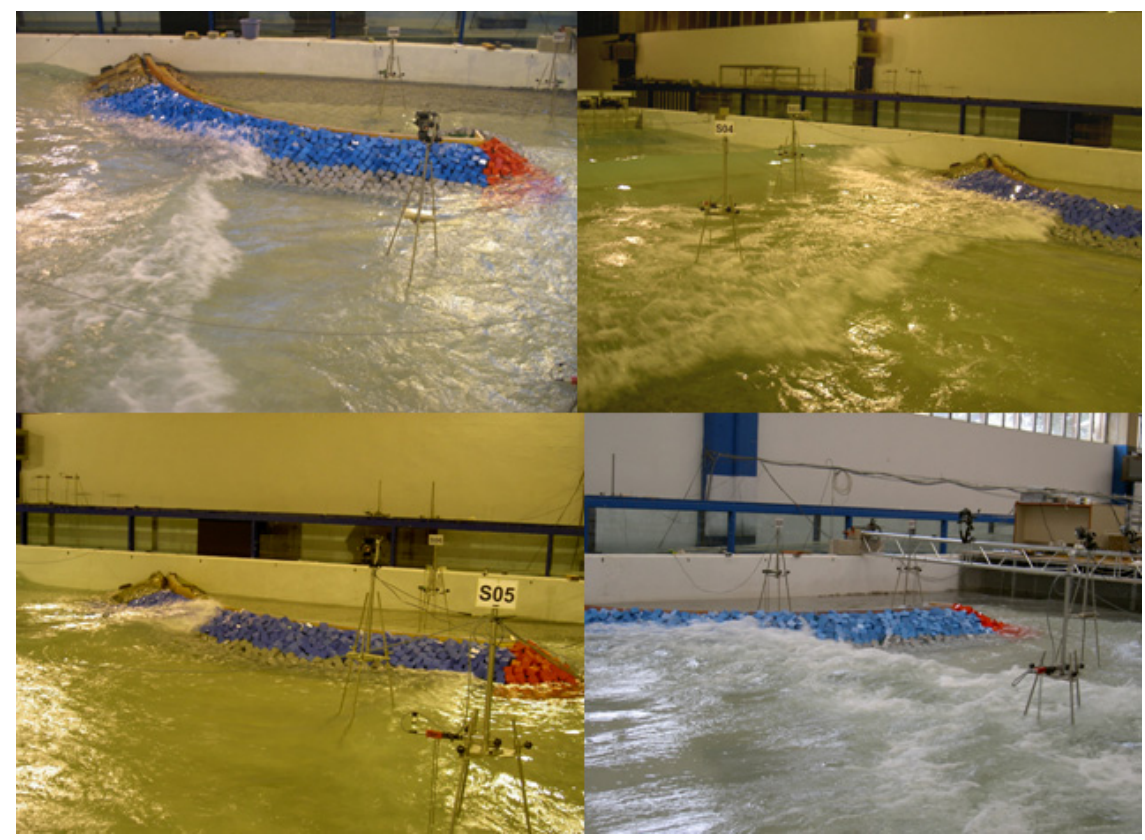

Figure 8. Wave run-up, energetic wave breaking, wave overtopping and high 3D propagation and agitation break patterns were collected and recorded during the experiments.

\section{Additional measurements}

Significant breaking, run-up, reflections and overtopping effects were observer during the experiments. These interesting wave transformations were captured thorough a camera and video system for all calibration and stability runs (see Fig. 8). These quantitative information would be used to validate the performance of any $2 \mathrm{DH}$ or/and 3D numerical model.

Finally, some modifications on the original position of the cubic units were photographed after each stability experiment; this information can be used in the future for a coupled hydrodynamic, stability numerical model in the future. 


\section{COMPARISON OF LABORATORY WAVES VS. NUMERICAL RUNS}

In this second section, a numerical comparison and validation of the experimental database acquisition showed above. As presented in this paper, this new database yields a new benchmark case for the validation and development of the corresponding numerical models (2DH and 3D) designed to propagate, transform and dissipate real wave trains with and without emerged harbour structures.

Especially interesting for any kind of engineering study related to 3D breaking, shoaling, diffraction and run-up over complex bathymetries, and from the trunk to the head of a breakwater.

Thus, the second aim of this paper is to demonstrate the value of the laboratory database, through the validation of a fully nonlinear and weakly dispersive Boussinesq model, solved by finite volume, which involves a fourth-order MUSCL-TVD scheme to solve the advection, (Kim et al. 2009). The model has been validated using classical benchmarks and real cases in (Armesto et al. under review 2012). The capability of the model to solve accurately the wave transformation towards the Laredo harbour is presented in this section.

\section{Overview of the model}

Within the family of depth-integrated numerical models for the study of wave propagating over real bottoms configurations, the Boussinesq-type equations were established as a consolidated alternative tool for propagate waves, from intermediate water depths to the coastal zones. Depending on the particular equation set, (Peregrine 1967); (Madsen et al. 1997); (Nwogu 1993); (Madsen et al. 2003), they accurately solve the non-linearity wave characteristics, as well as, wave reflection, nonstationary breaking and dissipation at beaches and coastal structures. Yet, the nonlinear and dispersive terms included in this family of equations, allows a realistic representation of the nearshore hydrodynamic processes (Hubbard and Dodd 2002); (Liang and Borthwick 2009), such shoaling, breaking, run-up and overtopping.

pCOULWAVE was original developed as a finite difference solver for the fully non-linear and weakly dispersive Boussinesq equations using different vertical layers (Lynett et al. 2002); (Lynett 2002); (Lynett and Liu 2004). (Lynett et al. 2002) validated this version of the co de with solitary waves propagation and run-up in 2DV cases, (Carrier and Greenspan 1958); (Synolakis 1987), and 2DH cases, (Briggs et al. 1995); (Peregrine 1969). Propagation and breaking of regular waves over an obstacle were validated using a 2DV case, (Dingemans 1994), and a 2DH case, (Vincent and Briggs 1989), in (Lynett and Liu 2004).

Finally (Lynett 2006) validated the code against irregular wave trains propagating over a beach using the 2DV laboratory cases of (Cox et al. 1995); (Ting and Kirby 1995, 1996). The model is very fast and reliable but it is sensible to fast shoaling waves propagating over steep slopes. To solve this problem, different authors have developed hybrid models to solve weakly non-linear and weakly dispersive Boussinesq equations which uses finite volume for advective terms and finite differences for dispersive terms, (Erduran et al. 2005); (Shiach and Mingham 2009); (Tonelli and Petti 2009). Following this trend, a second version of pCOULWAVE using finite volume method for both, advective and dispersive terms for the fully non-linear and weakly dispersive Boussinesq equations was presented by (Kim et al. 2009).

The new benchmark case previously presented is used to validate this model, including all the main bathymetric, wave, and dissipation characteristics of the experiments, as well as, the exact location of the wave gauges, target free surface time series and same measurement frequencies.

In the present study, two domains were designed, valid for both calibration and stability tests. The numerical wave tank was copied exactly from the real basin (see Fig. 7), and the regular mesh size was established with a 30 nodes per wavelength criteria, for each of the runs, a time step of $\Delta t=0.01 \mathrm{~s}$ was used, for the Courant condition for time step numerical stability. 

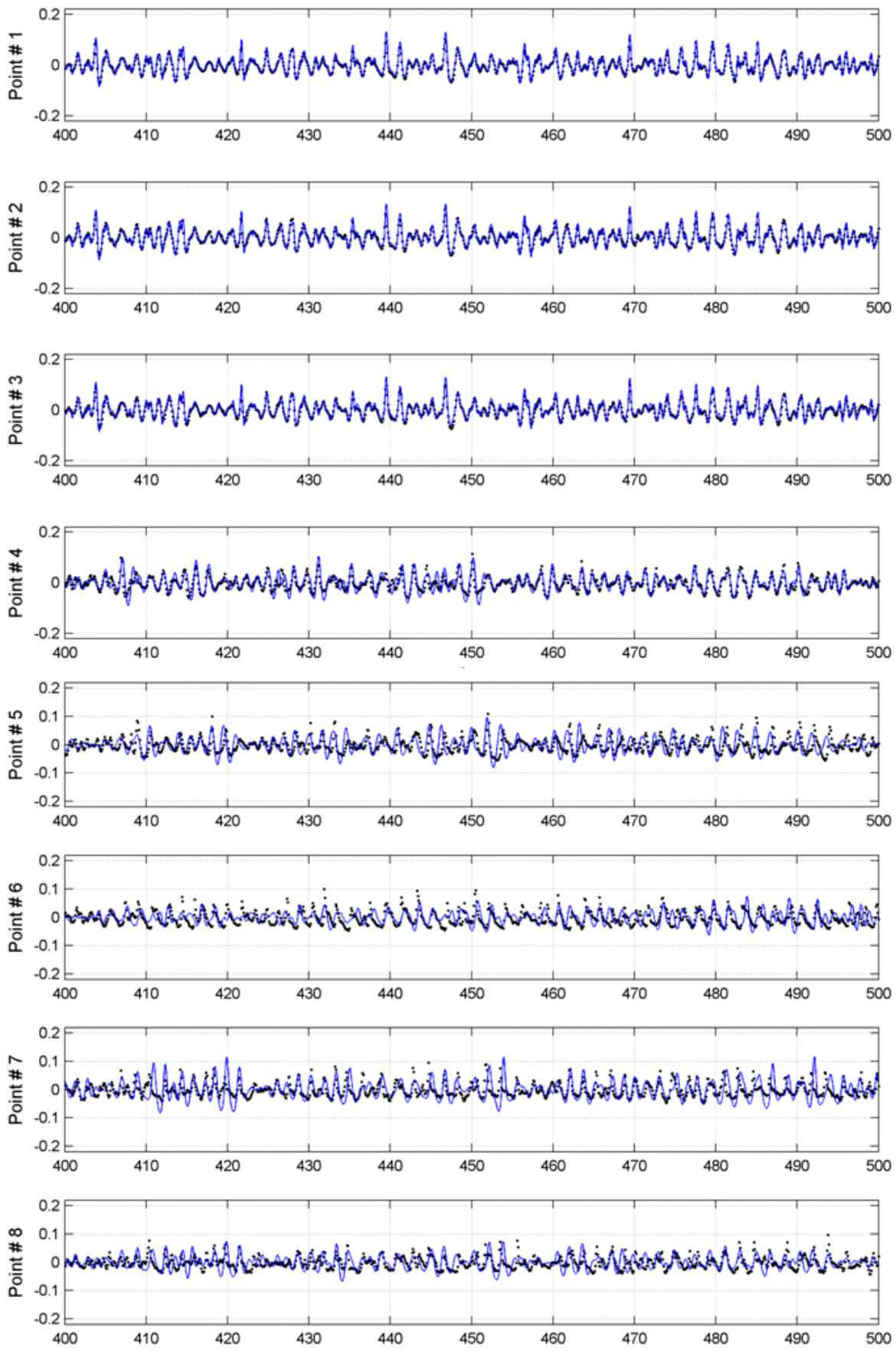

Figure 9. Test BMVE_h5p0_t12p0—comparison of measured (black points) and modelled (blue line) wave surface elevation time series, in the first 8 points.

\section{Analysis of the results and model verification}

In this section, some tests were selected to represent the performance of the numerical model. For each test, the time series of the free surface were plotted for both measured data and numerical model runs. Also, comparative between measurements and numeric results were carried out by a classical energy spectrum and the temporal variation of the wave energy by the wavelet spectrum representation. Finally, significant wave height and $H_{50}$ were calculated at the gauges position.

In this paper, free surface records, incident wave spectra, wavelet representation and the incident wave height distributions are compared for two tests: a calibration test, named $B M V E \_h 5 p 0_{-} t 12 p 0$ 
with $H s=0.112 \mathrm{~m}$, and $T p=1.70 \mathrm{~s}$ and low tide water level; and a stability test named PMVE_h5p0_t12p0 with $H s=0.20 \mathrm{~m} ; \mathrm{Tp}=2.74 \mathrm{~s}$ and high tide water level, were selected.
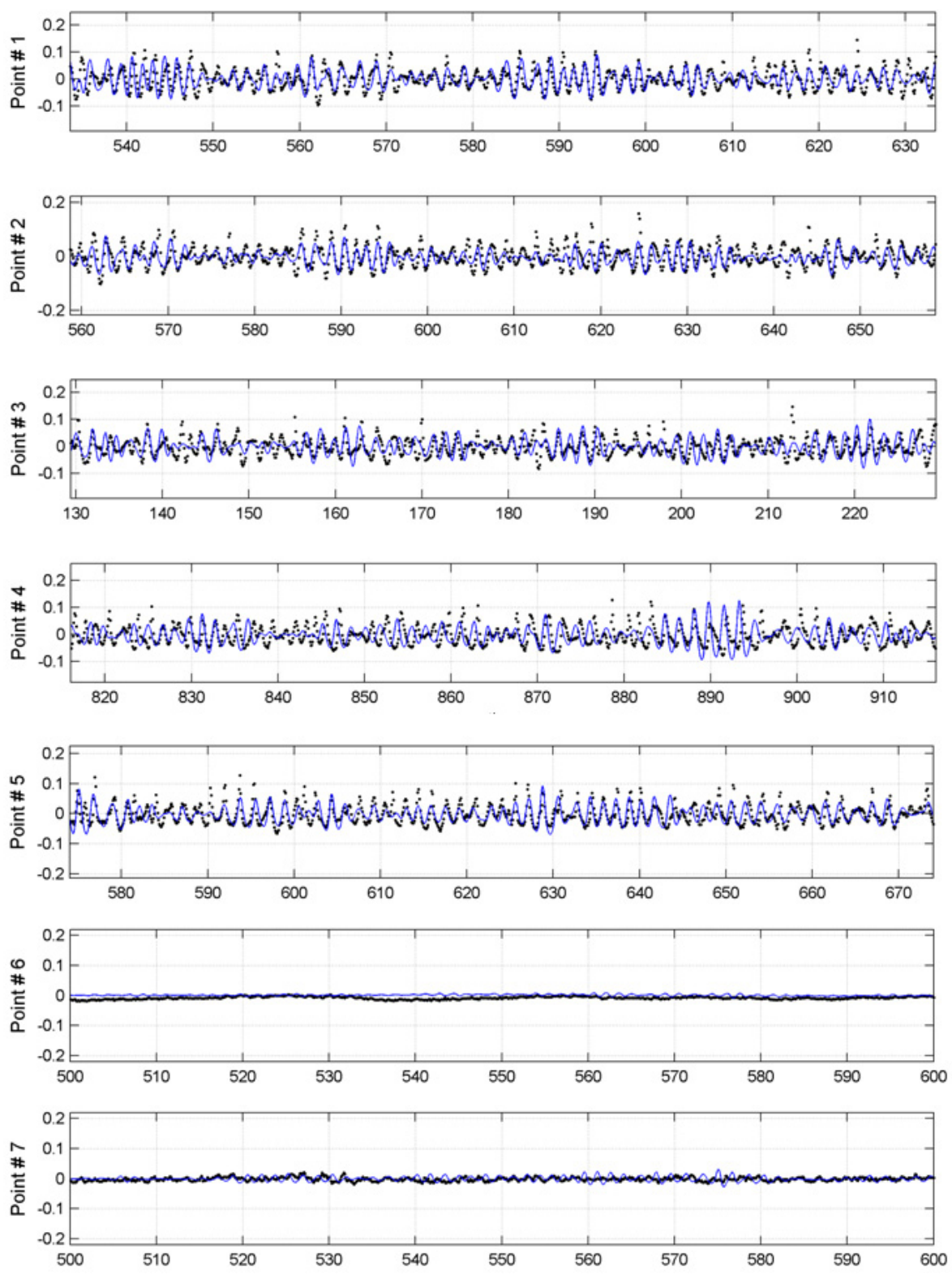

Figure 10. Test PMVE_h5p0_t12p0 - comparison of measured (black points) and modelled (blue line) wave surface elevation time series, in points 1 to 7.

These tests have been chosen as representative of the 33 simulations experimentally carried out, for both tide levels simulated and for a mid to high wave energy, in order to achieve the complexity of the wave breaking observed along the experiments.

Fig. 9 and 10 shows the performance of the numerical model, through the comparison of the free surface for the calibration and stability test mentioned above, for different times, showing a good agreement between laboratory and numerical data, even for the most complex propagation and agitation patterns for the stability experiments, where an important wave damping did occur in the lee zone of the structure. Furthermore, numerical models showed an excellent performance with the wave train evolution and numerical stability of the numerical scheme.

Very good agreements in propagation transformation of wave heights from the deeper zone of the wave tank, near the wave generation, to the closeness of the structure were observed in the numerical results. The change in wave height is mainly due to shoaling and breaking and in some cases due to the reflection at walls. For the largest wave steepness quite some wave breaking took place on the 
foreshore. This behaviour can be observed in the energy spectrum showed in Fig. 11 and 12 where both calibration and stability comparison are shown, for all the wave gauges used in the experimental runs, even for the sub-harmonic generation on time.
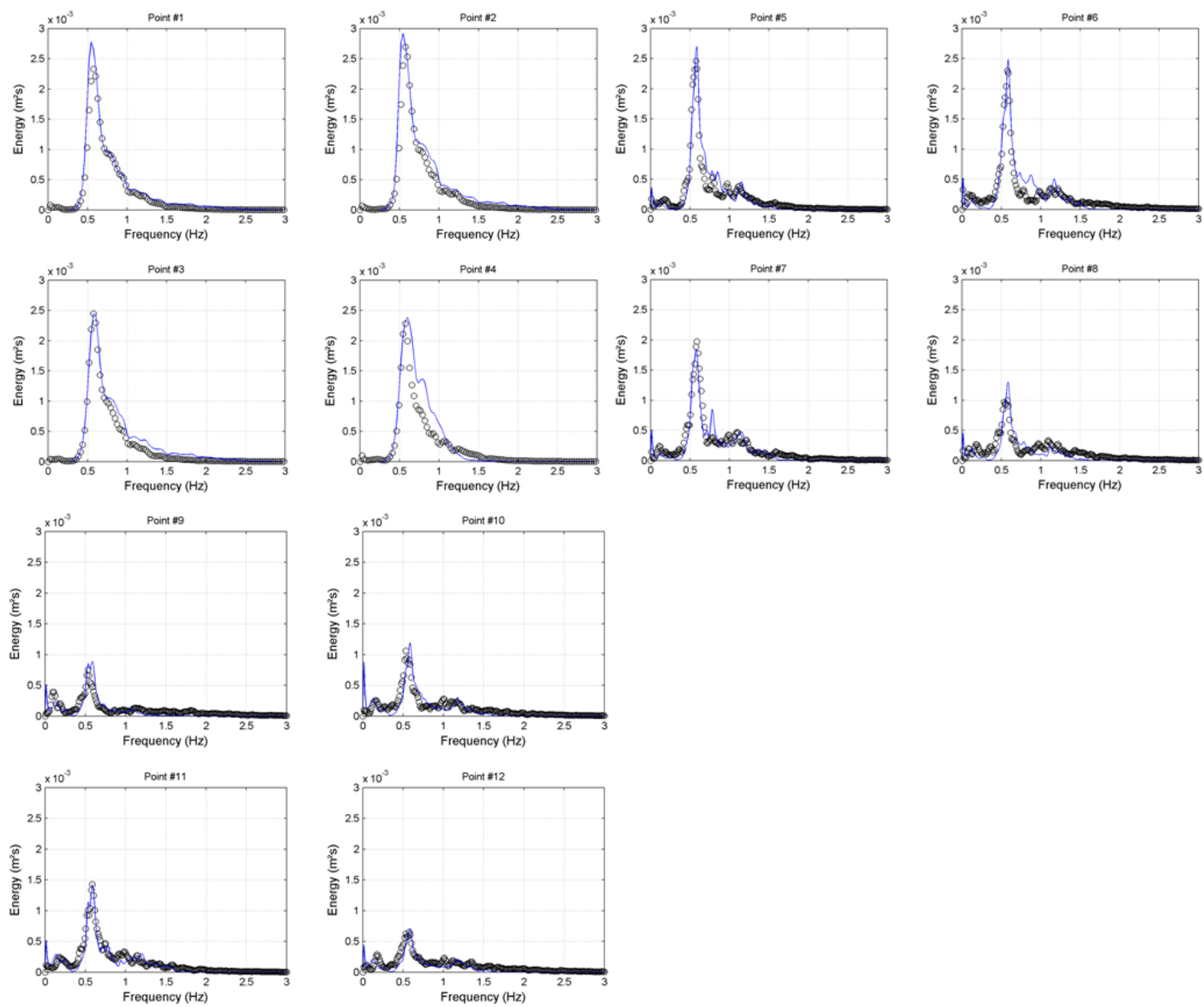

Figure 11. Test BMVE_h5p0_t12p0—comparison of energy spectrum for: measured (black circles) and modelled (blue line).
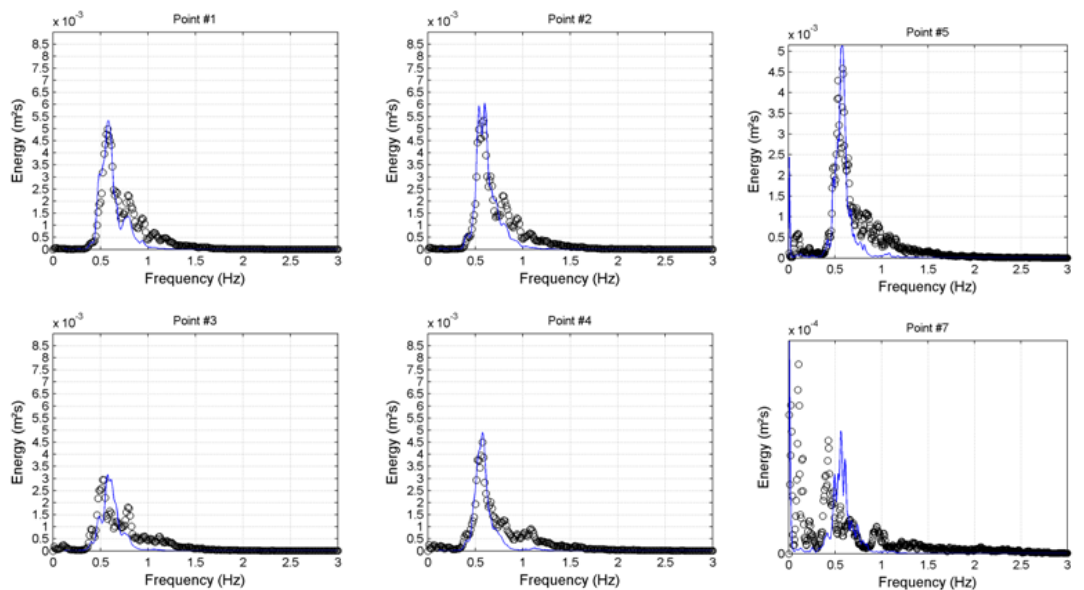

Figure 12. Test PMVE_h5p0_t12p0—comparison of energy spectrum for: measured (black circles) and modelled (blue line). 
The variation on time of the wave energy can be analyzed through a wavelet spectrum, as shown in Fig. 13 and 14. The evolution of the wave energy can be observed along white line, which represents the maximum energy evolution on time, and frequency. Numerical maximum energy evolution present a similar track compared to the measured wavelet. The wavelet representation for the experimental data presents the generation of super-harmonic, which is not well represented by the numerical model because the mesh size defined of 30 nodes per wavelength, maybe a finer mesh should be implemented in order to improve this energy transfer to the higher frequencies.
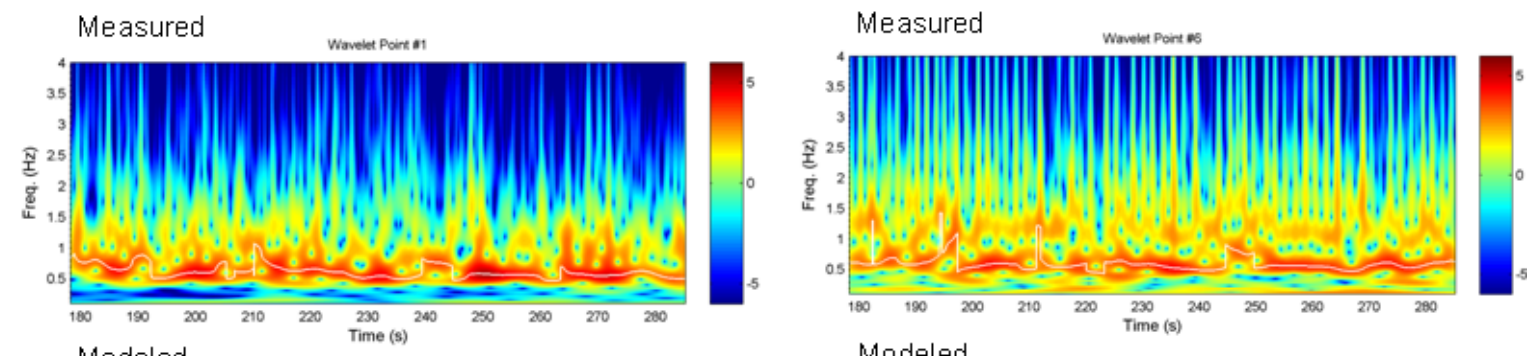

Modeled

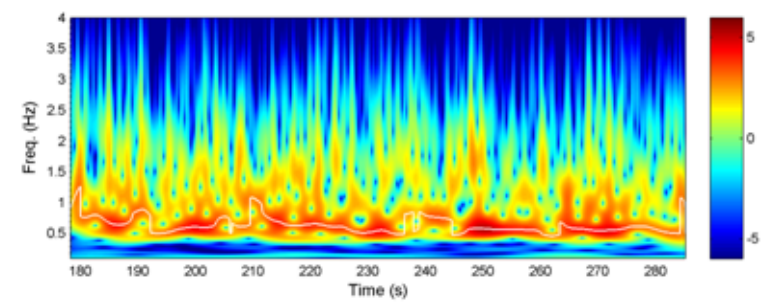

$$
\text { Modeled }
$$

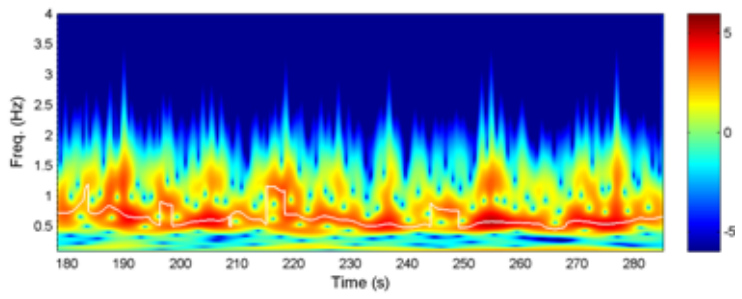

Figure 13. Test BMVE_h5p0_t12p0 - Time history and wavelet spectrum at different locations, points $1 \& 6$.
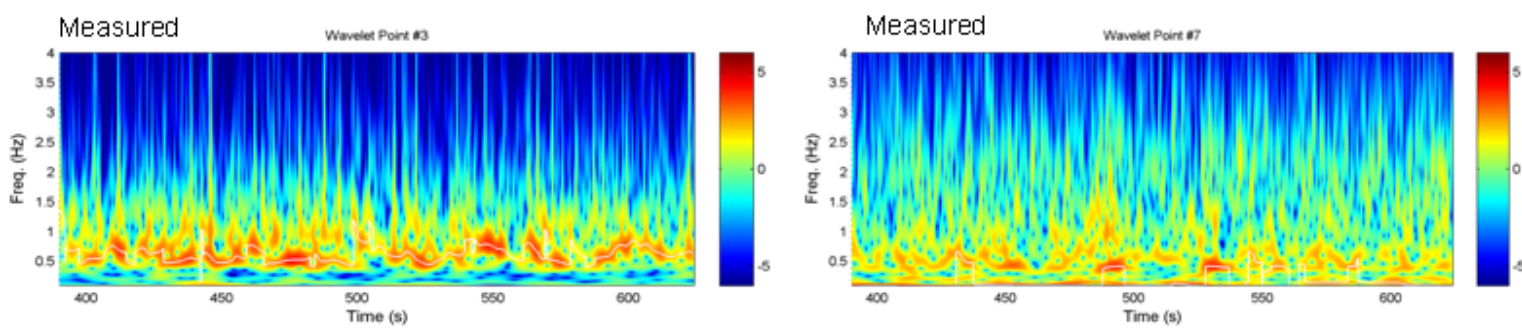

Modeled
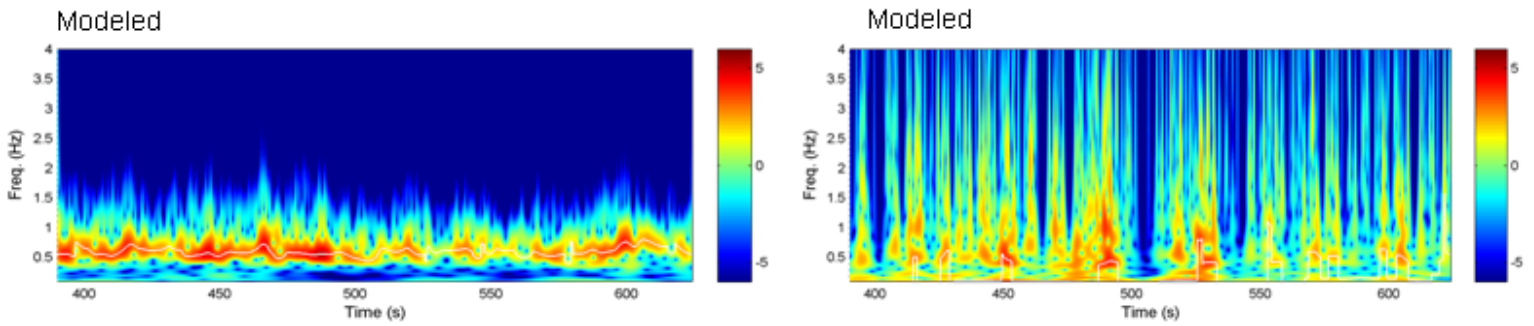

Figure 14. Test $P M V E \_h 5 p 0 \_t 12 p 0$ - Time history and wavelet spectrum at different locations, points $3 \& 7$.

Finally, Fig. 15 shows a comparison of the significant wave heights measured in both laboratory and numerical simulations for all wave gauges. The figure confirms the good behaviour of the numerical model, and demonstrates indirectly the good numerical representation of the energy conservation of the wave height evolution, transformation, propagation and dissipation phenomena observed in laboratory. 

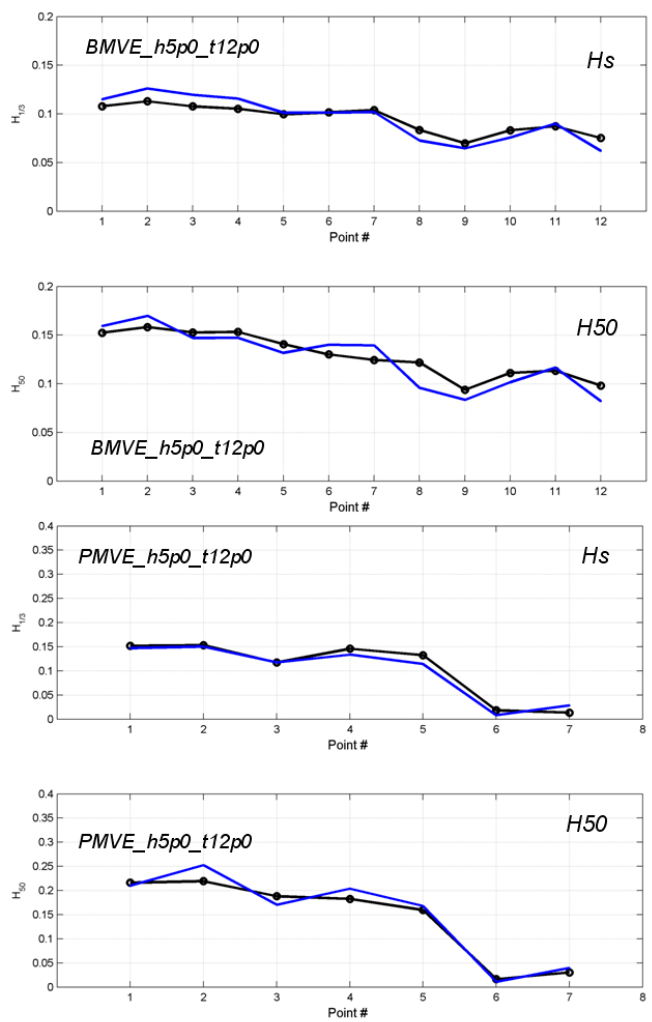

Figure 15. Significant wave height $H s$ and $H_{50}$ calculated along wave gauges position for numerical (black line) and measured (black line) data

\section{CONCLUSIONS}

In this research a new experimental database, provided as complete new benchmark case freely available for Coastal/Harbour Engineering community.

Wave transformation phenomena of special interest were identified (run-up, breaking, overtopping) within the wave basin and at the breakwater surroundings.

The pCOULWAVE model was validated in the present work in order to demonstrate the value of this new laboratory database. It showed that it was able to adequate predict irregular wave free surface for all the wave gauges, and even for the complex breaking, reflection and shoaling zones up to the breakwater region, for the stability runs.

In summary the value of this new free-use laboratory database for numerical model validation was demonstrated, hoping that any technical, coastal engineering or model developer would use this database in the future. 


\section{APPENDIX}

The following table summarizes the forcing wave height, maximum / minimum elevations for this new benchmark case.

\begin{tabular}{|c|c|c|c|}
\hline \multicolumn{5}{|c|}{ Table 1. Forcing characteristics for irregular } \\
wave. For low tide (BMVE)
\end{tabular}

\begin{tabular}{|c|c|c|c|}
\hline \multicolumn{5}{|c|}{ Table 2. Forcing characteristics for irregular } \\
wave. For high tide (PMVE)
\end{tabular}

\section{REFERENCES}

Armesto J.A., Diaz-Hernandez G., Losada I. J., (2012): Applicability and validation of pCOULWAVE to study engineering Problems. Coastal Engineering, (under review).

Bouws, E., H. Gunther, W. Rosenthal and C. L. Vincent (1985a) Similarity of the wind wave spectrum in finite depth water, Part I- Spectrum form. J. Geophys. Res., 90(C1), 975-986.

Chen, Q. R., Dalrymple, A., Kirby, T., Kennedy, A. \& Haller, M. C. 1999 Boussinesq modelling of a rip current system. J. Geophys. Res. 104, 20617-20637.

Cox, D.T., Kobayashi, N., Okayasu, A., 1995. Experimental and numerical modeling of surf zone hydrodynamics. Technical Report. CACR-95-07. Center for Applied Coastal Research, University of Delaware.

Desombre J., Morichon D., Mory M., RANS v2-f simulation of a swash event: Detailed flow structure, Coastal Engineering, Volume 71, January 2013, Pages 1-12, ISSN 0378-3839.

Erduran, K.S., Ilic, S., Kutija, V., 2005. Hybrid finite-volume finite-difference scheme for the solution of Boussinesq equations. International Journal for Numerical Methods in Fluid 49, 1213-1232.

Garcia, N., Lara, J. L., \& Losada, I. J. (2004). 2-D numerical analysis of near-field flow at low-crested permeable breakwaters. Coastal Engineering, 51(10), 991-1020. Retrieved from

Higuera P., LaraJ.L., Losada I.J., Simulating coastal engineering processes with OpenFOAM ${ }$, Coastal Engineering, Available online 19 July 2012, ISSN 0378-3839.

Hubbard, M.E., Dodd, N., 2002. A 2d numerical model of wave run-up and overtopping. Coastal Engineering 47, $1-26$.

Kennedy, A. B. \& Fenton, J. D. 1997 A fully-nonlinear computational method for wave propagation over topography. Coast. Engng 32, 137-161.

Kim, D.H., Lynett, P.J., Socolofsky, S.A. (2009): A depth-integrated model for weakly dispersive, turbulent and rotational fluid flows. Ocean Modelling. 27, 198-214.

Liang, Q., Borthwick, A.G., 2009. Adaptive quadtree simulation of shallow flows with wetdry fronts over complex topography. Computers \& Fluids 38, $221-234$. 
Losada, I. J., Lara, J. L., Guanche, R., \& Gonzalez-Ondina, J. M. (2008). Numerical analysis of wave overtopping of rubble mound breakwaters. Coastal Engineering, 55(1), 47-62.

Lynett, P., 2002. A two-dimensional, depth-integrated mo del for internal wave propagation over variable bathymetry. Wave Motion 36, 221-240.

Lynett, P.J., 2006. Nearshore wave modelling with high-order boussinesq-type equations. Journal of Waterway, Port, Coastal and Ocean Engineering, 348-357.

Lynett, P.J., Liu, P.L.F., 2004. A two-layer approach to wave modelling. Proc. Royal Soc., London, Series A 460, 2637-2669.

Lynett, P.J., Melby, J.A., Kim, D.H., 2010. An application of boussinesq modeling to hurricane wave overtopping and inundation. Ocean Engineering 37, 135 - 153.

Lynett, P.J., Wu, T.R., Liu, P.L.F., 2002. Moleling wave runup with depth-integrated equations. Coastal Engineering 46, 89 - 107.

Peregrine, D.H., 1967. Long waves on a beach. Journal of Fluid Mechanics 27, 815-827.

Madsen, P. A., Sörensen, O. R. \&. Schäffer, H. A. 1997 Surf zone dynamics simulated by a Boussinesq type model. Part 1. Model description and cross-shore motion of regular waves. Coast. Engng 32, 255-287.

Madsen, P.A., Sørensen, O., Schäffer, H.A., 1997. Surf zone dynamics simulated by a Boussinesq type model. Part II: surf beat and swash oscillations for wave groups and irregular waves. Coastal Engineering 32, 289-319.

Madsen, P.A., Bingham, H.B., Sch er, H.A., 2003. Boussinesq-type formulations for fully nonlinear and extremely dispersive water waves: derivation and analysis. Proceedings of the Royal Society of London. Series A: Mathematical, Physical and Engineering Sciences 459, 1075-1104.

Nwogu, O., 1993. Alternative form of boussinesq equations for nearshore wave propagation. Journal of Waterway, Port, Coastal, and Ocean Engineering 119, 618-638.

Shiach, J.B., Mingham, C.G., 2009. A temporally second-order accurate Godunov-type scheme for solving the extended Boussinesq equations. Coastal Engineering 56, 32-45.

Ting, F.C.K., Kirby, J.T., 1995. Dynamics of surf-zone turbulence in a strong plunging breaker. Coastal Engineering 24, 177-204.

Ting, F.C.K., Kirby, J.T., 1996. Dynamics of surf-zone turbulence in a strong spilling breaker. Coastal Engineering 27, 131-160.

Tonelli, M. and Petti, M. (2009). Hybrid finite volume - finite difference scheme for 2DH improved Boussinesq equations. Coastal Engineering, 56:609 - 620.

Vidal C., Medina R. Lomónaco P. 2006. Wave height parameter or damage description of rubblemound breakwaters. Coastal Engineering 53 (2006). 711 - 722. 